\title{
VIVENCIA DEL DERECHO \\ INTERNACIONAL PÚBLICO Y APROXIMACIONES PARA UNA CONCILIACIÓN HERMENÉUTICA \\ DE LOS ARTÍCULOS 26 Y 62 dE LA CONVENCIÓN DE VIENA DE 1969
}

The Reality of Public International LAW and Approximations to a Hermeneutic Conciliation between Articles 26 and 62 of the Vienna Convention of 1969

VIVÊNCIA DO DIREITO INTERNACIONAL PÚBLICO E APROXIMAÇÕES PARA UMA CONCILIAÇÃO HERMENÊUTICA DOS ARTIGOS 26 E 62 dA ConVENÇÃo DE VIENA DE 1969

ANDRÉS TÉLLEZ NÚÑEZ*

orcid.org/0000-0002-6775-4101. Pontificia Universidad Javeriana, Colombia. aatellez@javeriana.edu.co

RECIBIDO: O6 DE FEBRERO DE 2018. ENVÍO A PARES: O7 DE FEBRERO DE 2018

APROBADO POR PARES: 18 DE ABRIL DE 2018. ACEPTADO: O2 DE MAYO DE 2018

DOI: $10.5294 / D I K A .2018 .27 .2 .2$ ANDRÉS TÉLLEZ NÚÑEZ, "VIVENCIA DEL DERECHO INTERNACIONAL PÚBLICO Y APROXIMACIONES PARA UNA CONCILIACIÓN HERMENÉUTICA DE LOS ARTÍCULOS 26 Y 62 DE LA CON- 


\section{RESUMEN}

De una lectura sistemática de los artículos 26 y 62 de la Convención de Viena de 1969 podría inferirse una aparente contradicción para el intérprete. La primera disposición, que establece el principio pacta sunt servanda, y la segunda, que contiene la cláusula rebus sic stantibus, en el contexto del derecho de los tratados, indicarian que ellas operan entre sí como regla y excepción respectivamente. Sin embargo, en el marco de una investigación hermenéutica sobre la realidad del derecho internacional público contemporáneo, que tiene a los Estados como textos vivientes y que busca auscultar qué hay detrás, no solo de las normas escritas, sino también de la conducta de los sujetos de derecho internacional, este artículo propone una hipótesis de trabajo consistente en afirmar que lo que se llama derecho internacional público coincide con la práctica actual de los Estados, y que lejos de lo afirmado por la Declaración de Londres de 1871, antecedente medianamente remoto de la cláusula rebus sic stantibus, los Estados siempre serán jueces de sus propias conductas, no en el sentido de litigio, sino en el sentido de un conjunto de valoraciones continuas bajo una óptica hermenéutica. Para demostrar la hipótesis de trabajo se recurre a una aproximación multidimensional que cubre, entre otras herramientas de análisis, el law and economics y el derecho internacional de la inversión extranjera.

\section{Palabras CLAVE}

Pacta sunt servanda; rebus sic stantibus; tratados; derecho internacional público; hermenéutica; Carta de las Naciones Unidas; Convención de Viena. 


\section{ABSTRACT}

A systematic look at articles 26 and 62 of the Vienna Convention of 1969 could give the impression of an apparent contradiction between them, for the interpreter. In the context of the law of treaties, the first provision establishes the principle of pacta sunt servanda, and the second contains the rebus sic stantibus clause. This would seem to indicate they operate with respect to each other as both a rule and an exception. However, within the framework of a hermeneutic study on the reality of contemporary public international law, with States viewed as living texts and an effort being made to examine not only what is behind the written norms, but also the conduct of the subjects of international law, this article proposes a working hypothesis based on the idea that what is known as public international law matches the current practice of States, and that far from what was affirmed by the London Declaration of 1871, which can be deemed as a remote forerunner of the rebus sic stantibus clause, States will always be judges of their own conduct, not in the sense of litigation, but in the sense of a set of continuous value judgements from a hermeneutic or cost-benefit perspective. To demonstrate this hypothesis, the authors resort to a multidimensional approach that covers, among other analytical tools, the law and economics and international law on foreign investment.

\section{KEYWORDS}

Pacta sunt servanda; rebus sic stantibus; treaties; public international law; hermeneutics; Charter of the United Nations; Vienna Convention. 


\section{RESUMO}

De uma leitura sistêmica dos artigos 26 e 62 da Convenção de Viena de 1969, poderia ser inferida uma aparente contradição para o intérprete. A primeira disposição, que estabelece o princípio pacta sunt servanda, e a segunda, que contém a cláusula rebus sic stantibus, no contexto do direito dos tratados, indicariam que elas operam entre si como regra e exceção respectivamente. Contudo, no âmbito de uma pesquisa hermenêutica sobre a realidade do direito internacional público contemporâneo, que tem os Estados como textos viventes e que busca examinar o que há por trás, não somente das normas escritas, mas também do comportamento dos sujeitos de direito internacional, este artigo propõe uma hipótese de trabalho consistente em afirmar que o que se chama direito internacional público coincide com a prática atual dos Estados e que, longe do afirmado pela Declaração de Londres de 1871, antecedente moderadamente remoto da cláusula rebus sic stantibus, os Estados sempre serão juízes de suas próprias condutas, não no sentido de litígio, mas sim no de um conjunto de avaliações contínuas sob uma ótica hermenêutica. Para demonstrar a hipótese de trabalho, recorre-se a uma aproximação multidimensional que cobre, entre outras ferramentas de análise, o law and economics e o direito internacional do investimento estrangeiro.

\section{PALAVRAS-CHAVE}

Pacta sunt servanda, rebus sic stantibus, tratados, direito internacional público, hermenêutica, Carta das Nações Unidas; Convenção de Viena. 
SUMARIO: INTRODUCCIÓN. 1. APROXIMACIÓN MULTIDIMENSIONAL A UN PROBLEMA HERMENÉUTICO. ¿EXISTE UN CONFLICTO ENTRE LOS ARTíCuLOS 26 Y 62 DE LA CONVENCIÓN DE VIENA DE 1969? 1.1. QUÉ ES LO QUE DENOMINAMOS PROBLEMA HERMENÉUTICO. 1.2. APROXIMACIONES MULTIDIMENSIONALES AL PROBLEMA HERMENÉUTICO. 2. HACIA UNA PROPUESTA DE SOLUCIÓN DEL PROBLEMA HERMENÉUTICO: LA DIVERSIDAD DE INTERPRETACIONES. 3. CONCLUSIÓN. BIBLIOGRAFíA

\section{INTRODUCCIÓN}

Hay dos temas propios de la aplicación y la interpretación ${ }^{1}$ de las normas jurídicas de derecho internacional público (DIP). Por un lado, el paso del tiempo y, por otro, las motivaciones tanto de los seres humanos como de los Estados y sus representantes para actuar de una u otra forma, aparte de considerar sus actos mismos.

Creemos que ellos van ligados en la medida en que la realidad que tomamos como equivalente al mundo del ser (is) se ve inevitablemente permeada al momento de ser observada por la percepción y vivencia del tiempo cronológico, por la entrada incesante de nuevos actores y por la materialización de nuevos hechos y actos.

En el fondo, los dos temas que serán objeto de discusión y análisis en este artículo se materializan en el principio pacta sunt servanda (PSS) consagrado en el artículo $26^{2}$ de la Convención de Viena de 1969 (CV), y en la doctrina rebus sic stantibus (RSS), contenida en el artículo $62^{3}$ de la CV.

Queremos concentrarnos a lo largo de este manuscrito en estos dos artículos de la CV, como leitmotiv para reflexionar más ampliamente sobre la existencia del DIP y, en forma correspondiente, hacer énfasis en los dos temas referidos para demostrar la siguiente hipótesis de trabajo: que hay una coincidencia entre i) la vivencia del DIP por parte de los Estados y ii) el significado y alcance de lo que es DIP. ${ }^{4}$

1 Tomamos la interpretación como una especie de aplicación de la norma jurídica.

2 Este artículo dispone lo siguiente: "Pacta sunt servanda. Todo tratado en vigor obliga a las partes y debe ser cumplido por ellas de buena fe".

3 Este artículo dispone lo siguiente: "Cambio fundamental en las circunstancias. 1. Un cambio fundamental en las circunstancias ocurrido con respecto a las existentes en el momento de la celebración de un tratado y que no fue previsto por las partes no podrá alegarse como causa para dar por terminado el tratado o retirarse de él a menos que: a) la existencia de esas circunstancias constituyera una base esencial del consentimiento de las partes en obligarse por el tratado, y b) ese cambio tenga por efecto modificar radicalmente el alcance de las obligaciones que todavia deban cumplirse en virtud del tratado. 2. Un cambio fundamental en las circunstancias no podrá alegarse como causa para dar por terminado un tratado o retirarse de él: a) si el tratado establece una frontera; o b) si el cambio fundamental resulta de una violación por la parte que lo alega, de una obligación nacida del tratado o de toda otra obligación internacional con respecto a cualquier otra parte en el tratado. 3. Cuando, con arreglo a lo dispuesto en los párrafos precedentes, una de las partes pueda alegar un cambio fundamental en las circunstancias como causa para dar por terminado un tratado o para retirarse de él, podrá también alegar ese cambio como causa para suspender la aplicación del tratado".

4 Esta hipótesis se aborda, pero con otros elementos, en Andrés Téllez Núñez, El problema de la efectividad del derecho internacional público, Bogotá, Pontificia Universidad Javeriana, 2008, pp. 1-10. 
Con el fin de proceder con dicha demostración recurriremos principalmente a una observación hermenéutica del proceso de interpretación y de aplicación de las normas jurídicas, términos que asumimos como sinónimos en el cuerpo del DIP.

Esto quiere decir que no solo buscaremos escudriñar el significado de un texto escrito, específicamente un tratado, sino que adicionalmente auscultaremos las motivaciones, el subtexto y el comportamiento mismo de los Estados y de sus representantes, en adelante, ambos, agentes, a la luz del PSS y la cláusula RSS establecidos correspondientemente en los artículos 26 y 62 de la CV.

Ello nos llevará a revisar lo que llamaremos ampliamente el problema hermenéutico, y a recurrir a aproximaciones multidimensionales, específicamente algunas dadas por el derecho internacional de la inversión extranjera, por el law and economics, y por ciertas consideraciones de corte filosófico-psicológico.

Para efectos de demostrar nuestra hipótesis de trabajo hemos utilizado un método empírico-hermenéutico por virtud del cual se recurre a la observación y crítica de datos ambientales, lo cual nos servirá para concluir que el DIP es, en efecto, aquel vivido y experimentado por los Estados-nación hoy a través de su conducta y que coincide con ella. ${ }^{5}$

Nuestro método de trabajo, en aras de demostrar la hipótesis, supone las siguientes aristas: i) preguntarnos a la luz de la cláusula RSS y del principio PSS si un Estado es o puede ser o no juez de su propia causa, no en el sentido de litigio, es decir, como un proceso judicial ante la Corte Internacional de Justicia (CIJ), o ante un tribunal arbitral, sino en un sentido hermenéutico, esto es, como conjunto de valoraciones sucesivas y continuas que hacen los agentes sobre el movimiento y tráfico de las relaciones exteriores e internacionales que son susceptibles de ser interpretadas y, además, qué significa todo ello, y ii) abordar el problema de significantes y significados en torno a discursos y palabras concretas en el marco de las relaciones internacionales.

Antes de entrar a discutir en detalle los intringulis de lo que denominamos el problema hermenéutico, queremos proponer al lector un primer ejemplo que puede ilustrar la excursión que ahora pretendemos emprender.

Supongamos un Estado A, un Estado B y un Estado C. En un momento $x$, estos Estados suscriben lo que bajo las normas de la CV se denomina tratado. La realidad, que para efectos de nuestro artículo hacemos equivalente al mundo del ser o

5 Una tesis consiste en afirmar que el derecho internacional público efectivo es aquel vivido por una entidad cualquiera con mayor poder político relativo, que tendremos como imperio, y solo y en la medida en que sea un régimen democrático que sigue una definición moderna de democracia liberal, cuyas notas no alcanzamos a describir con detalle en este manuscrito. Para tildar de efectivo al derecho internacional público, y con el ánimo de defender esa tesis, el cuerpo de normas también podría dividirse en dos: aquellas de corte económico, el llamado derecho internacional económico, y aquellas de corte más político, que tienen que ver con seguridad y paz internacionales. Creemos que el primero tenderá a ser relativamente más efectivo que el segundo. 
mundo externo, por parte de los agentes en ese momento $x$, tiene unos contornos vistos que en un momento $z$ variarán y que se verán reflejados en un conjunto de valoraciones sucesivas por parte de los agentes.

¿Cómo debe lidiar el estudioso de las normas de DIP con este paso del tiempo y en torno a esas valoraciones? ¿Cómo conciliar el principio PSS con las necesidades de un Estado en un momento en particular de su existencia y con la eventual aplicación o invocación del artículo 62 de la CV? ¿Qué soluciones jurídicas, pero en ocasiones extralegales, pueden dársele a ese problema? ¿Es ese al final un problema digno de consideración?

Este artículo se divide en dos grandes partes. La primera presenta una aproximación multidimensional y multidisciplinaria que busca dar luces acerca de cómo resolver el problema hermenéutico y, más concretamente, delinear criterios en torno a una presunta, aparente o inexistente contradicción entre los artículos 26 y 62 de la CV, reiteramos, en el marco más amplio de una reflexión sobre la existencia del DIP. Para ello recurrimos a algunos hallazgos en materia de derecho internacional de la inversión extranjera, el law and economics, y a algunas tesis que soportan nuestra hipótesis de trabajo en torno a un examen hermenéutico de la conducta y el comportamiento de los Estados.

La segunda parte busca delinear una propuesta de solución al problema hermenéutico sobre la base de un conflicto de interpretaciones, no solo respecto del texto escrito, sino también de la conducta de los mismos Estados, estos últimos que tomaremos o asumiremos como normas vivas o vivientes. En dicha parte recurriremos a la exposición de un par de situaciones fácticas, específicamente la apelación a la mención por vía de ejemplo de algunos tratados, a fin de solidificar la demostración de nuestra hipótesis de trabajo.

\section{APROXIMACIÓN MULTIDIMENSIONAL A UN PROBLEMA HERMENÉUTICO ¿EXISTE UN CONFLICTO ENTRE LOS ARTÍ́Culos 26 Y 62 dE LA CONVENCIÓN DE VIENA DE 1969?}

\subsection{Qué es lo que denominamos problema hermenéutico}

Queremos significar por problema hermenéutico aquel representado por los siguientes elementos: i) una aparente tensión o divorcio entre el texto escrito contentivo de una norma jurídica de DIP y la conducta de los agentes con respecto a dicho texto; pensemos, a guisa de ejemplo, en el artículo 2 (4) de la Carta de las Naciones Unidas (Carta de la ONU); ii) una búsqueda para entender por qué un agente actúa de tal o cual forma dado el paso del tiempo cronológico.

El ámbito i) lo denominaremos de manera amplia como un asunto de existencia, de efectividad y de eficacia, y el ámbito ii) lo denominaremos ampliamente como un conflicto de interpretaciones. 
Subyacente a estos dos ámbitos representados por el problema hermenéutico, nos encontraremos con lo que hemos aceptado ya por muchos años y que consiste en una sinonimia entre derecho y política, que tiene como base aquella expresión atribuida a Louis Henkin, según la cual law is politics, ${ }^{6}$ que contradeciría, quizás solo en principio, lo afirmado por Bederman en el sentido de que entre fines del siglo XVIII y mediados del XIX, en gran parte de Europa, los campos del derecho y la politica se encontraban nitidamente diferenciados. ${ }^{7}$

En ese sentido, el lector deberá advertir que el problema hermenéutico se aborda aquí sobre la base de este entendimiento, y que el esfuerzo filosófico y jurídico aquí contenido, consistente en entender qué hay detrás de la vivencia del DIP por parte de los agentes, partirá de la base de esa equivalencia y de nuestra total aceptación de la misma.

\subsection{Aproximaciones multidimensionales al problema hermenéutico}

¡Empecemos por reafirmar que el DIP existe! El problema hermenéutico aquí no se contrae tanto a responder si existe o no porque, entre otras cosas, ya el solo hecho de que hablemos de él evidencia su existencia, sino más bien a determinar qué entendemos por él, luego de una comparación con la conducta de los agentes.

Si el hecho económico permea siempre la conducción de las relaciones internacionales, ${ }^{8}$ no podremos dejar de acudir aquí también a algunos hallazgos en el contexto de la inversión y de las promesas que los países en desarrollo han hecho a países desarrollados (los inversionistas), los cuales les han generado expectativas, aparte, claro está, de otros planteamientos que critican las tradicionales posturas de derecho natural y de derecho positivo.

Cohen identifica las que él llama intuiciones que plagan el DIP, que nos sirven para ambientar la discusión aquí delineada en torno a su existencia y efectividad, y que son las siguientes: i) aquellas según las cuales las normas de DIP son viola$\operatorname{das}^{9}$ ordinariamente, y ii) siguiendo a Louis Henkin, aquellas que permiten concluir que casi todos los Estados observan casi todos los principios y cumplen casi todas sus obligaciones casi todo el tiempo.

Así, de acuerdo con Cohen, podriamos estar tranquilos los seres humanos y, en particular, los estudiosos y críticos del DIP, al observar que en virtud de este pode-

6 Lori F. Damrosch, Louis Henkin, Richard Crawford, Oscar Schachter y Hans Smit, International Law Cases and Materials, West, 2001, p. 1.

7 David J. Bederman, "The 1871 London Declaration, rebus sic stantibus and a primitivist view of the law of Nations", en American Journal of International Law 82 (1988), p. 7.

8 Ver nota 5.

2129 Entendemos por violación para efectos de este manuscrito, la situación fáctica en que los agentes o no actúan de manera idéntica a lo previsto por una norma jurídica escrita o realizan un supuesto de prohibición allí contenido o se comportan en forma opuesta a lo descrito en el texto correspondiente, a la luz de un entendimiento y comprensión semánticos básicos, lógica formal y sentido común. 
mos consultar la hora internacional y la fecha siempre; existe la posibilidad real de enviar cartas por el correo internacional; tenemos la posibilidad de evitar la doble tributación en diferentes jurisdicciones y, en general, un laudo arbitral internacional puede hacerse efectivo en un foro extranjero. Con esto, Cohen prueba su hipótesis en el sentido de que el derecho internacional se cumple. ${ }^{10}$

Webb, por ejemplo, en el marco de una discusión sobre los alcances del PSS en los tratados bilaterales de inversión (BIT), arguye vía Andrew Guzmán, que podría verse como principal impedimento al desarrollo económico de los países en desarrollo por vía de la inversión extranjera, el que estos cambien sus políticas de manera tal que se dañen y perjudiquen los intereses tanto de los inversionistas como de la misma inversión. ${ }^{11}$

En ese sentido, una conducta que neutralizaria esa circunstancia indeseable sería (por lo menos) hacerle creer al inversionista que hay pocas o nulas posibilidades de que una situación legal desfavorable llegue a materializársele en una fecha posterior. ${ }^{12}$

En un contexto histórico, Webb nos recuerda, vía Andrew Guzman, y para criticar la tesis de este último, ${ }^{13}$ los esfuerzos de los países en vias de desarrollo por derogar normas de derecho consuetudinario en materia de exigencia de garantias a favor de los inversionistas extranjeros, evidenciada por ejemplo con la Carta de Derechos y Deberes Económicos de los Estados de 1974, que habría eliminado la llamada Hull Rule, ${ }^{14}$ y cuyo artículo 2 podría interpretarse en el sentido de que una compensación por expropiación no se requiere necesariamente en todas las circunstancias.

Lo mismo ocurre con las resoluciones 626 de 1952 y 1803 de 1962, de la Asamblea General de la Organización de las Naciones Unidas, que correspondientemente establecieron o reafirmaron la soberanía de los Estados sobre los recursos naturales y la necesidad de una compensación apropiada (appropriate en inglés) más que adecuada (adequate en inglés), junto con una reafirmación de que las promesas hechas a los inversionistas extranjeros son legalmente vinculantes, ${ }^{15}$ lo cual, en opinión de Karol N. Gess, representaría una reafirmación positiva de los principios de derecho internacional. ${ }^{16}$

10 Harlan Grant CoHen, "Finding international law: Rethinking the doctrine of sources", en Iowa Law Review 93 (2007), p. 67. Nosotros, por nuestra parte, entendemos por cumplimiento para efectos de este manuscrito lo que es opuesto a violación en el sentido referido en la nota anterior y, además, aquella situación en que no hay una conducta explícita de los agentes que haga que la norma jurídica sea violada, es decir, no se busca el cumplimiento por parte de los agentes, sino que el DIP se realiza sin la intervención de ellos.

11 Jason WebB YAскеE, "Pacta sunt servanda and state promises to foreign investors before bilateral investment treaties: Myth and reality", en Fordham International Law Journal 32 (2009), p. 1558.

12 Ibid., p. 1559.

13 Ibid.

14 Es decir, compensación pronta, adecuada y efectiva.

15 WebB YAckeE, "Pacta sunt servanda and state promises to foreign investors before bilateral investment treaties: Myth and reality”, op. cit., pp. 1561-1562.

16 Ibid., p. 1562. 
Andrew Guzmán afirma que, paradójicamente, los Estados en desarrollo que, según él, buscaron con los precitados instrumentos destruir una regla de compensación, con los BIT terminaron por reafirmar el principio de que una vez se viole una expectativa que a su vez cause un daño, este debe ser reparado por medio de una indemnización.

Webb no lo cree así, en parte, por el cambio ideológico que vivieron muchos países en desarrollo, que pasaron de defender una teoría de la dependencia a aceptar las concepciones neoliberales del llamado Consenso de Washington, ${ }^{17}$ aun cuando reconoce que los estudios de Eric Neumayer y Laura Spess, o de Ryan J. Bubb y Susan Rose-Ackerman ${ }^{18}$ en materia de los efectos de los BIT sobre los índices de inversión extranjera se basaron ampliamente en los hallazgos de Andrew Guzmán en el sentido de haber atribuido a los Estados en desarrollo el propósito de no cumplir las promesas hechas a los inversionistas.

Así, los países en desarrollo, en opinión de Webb, jamás habrian querido destruir una regla de compensación adecuada o apropiada y, a través de ello, quitarle todo significado, valor y eficacia al principio PSS. ${ }^{19}$

Al final, Webb, como nosotros, concluye que ese principio no ha dejado de tener vigencia o validez o eficacia (por ahora, en el sentido corriente de esos términos en español), sino que debe ser interpretado de manera flexible. ${ }^{20}$

Esto habria encontrado soporte, incluso antes de la CV, por ejemplo en: i) el arbitramento de Lena Goldfield, en donde el asunto del enriquecimiento injusto y la apelación a principios generales resulta ser un antecedente para entender el desarrollo del derecho internacional de la inversión extranjera, y ii) en el laudo arbitral Aramco de $1958^{21}$ que puede considerarse como la primera decisión arbitral moderna que arguye que el principio PSS siempre podrá ser utilizado para oponerse a un incumplimiento alegado con base en la soberania de un Estado.

En otras palabras: por virtud de la soberania, un Estado se obliga a algo. Tiempo después, no puede alegar su propia soberanía para incumplir lo que ha prometido antes. El éxito de la Cámara de Comercio Internacional, además y por vía de ejemplo, reafirmaria todavía más la importancia y fuerza del PSS. ${ }^{22}$

Por su parte, Hasan S. Zakariya, citado por Webb, ${ }^{23}$ arguye que el movimiento de soberanía permanente significa que siempre habrá de equilibrarse el principio PSS con el significado de RSS.

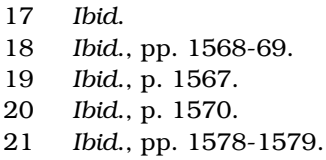


Según Bederman, una tensión entre ellos lo que hace es expresar las diferentes visiones del derecho internacional que, afirma él, es una invención moderna cuyo nombre puede atribuirsele a Jeremías Bentham. ${ }^{24}$

Moskvan afirma que los BIT son una creación de países europeos occidentales y su hallazgo parece ser más tradicional que el de Bederman.

Así, a la luz del derecho europeo, al invocar la doctrina de RSS, un Estado miembro de la Unión Europea $x$ tendría que argumentar el cambio de circunstancias ante otro Estado parte $w$, y si $w$ no somete el asunto ante un tribunal internacional, entonces $x$ podría declararse liberado de sus obligaciones desde el momento de la solicitud, ${ }^{25}$ con la anotación de que la imprevisibilidad en las cortes europeas vendría a ser interpretada de manera muy limitada, y que serían mayores los problemas en caso de que una parte decidiera objetar la aplicación de la cláusula RSS. ${ }^{26}$

Glennon arguye que la excesiva violación de una norma de DIP supone que ella será reemplazada, finalmente, por otra norma que permita una mayor libertad de acción.

En ese sentido, un comportamiento o conducta negativos ocurren cuando el beneficio de una violación es mucho mayor que los costos que puede asumir un número suficiente de Estados y, además, una violación por un cierto número de Estados, que sea significativo, termina por equivaler a que lo que era una violación, en realidad no lo sea.

Glennon arguye que para entender este fenómeno puede utilizarse el modelo de rational choice, que los Estados rara vez quebrantarian. ${ }^{27}$ Este autor opone teóricamente este modelo a las dos explicaciones tradicionales, derecho natural y positivismo, que seguirian a su vez dos categorías tradicionales de la filosofia occidental: racionalismo y empirismo.

A la postura positivista se le criticará que si, en efecto, la arquitectura normativa internacional se basa en el consentimiento, ¿por qué entonces los Estados no tienen la opción de retirar su consentimiento frente a una regla que a ellos no les gusta más?

Sin perjuicio de una precisión terminológica que haríamos en torno a la tesis de Glennon, en el sentido de que la misma CV permite no solo retirar la manifestación del consentimiento (arts. 18 y 68 de la CV), sino también denunciar un tratado o retirarse de él, lo que en ningún momento le resta eficacia o efectividad al principio de PSS, el rational choice model, según él, explicaría todo el embrollo

24 Bederman, "The 1871 London Declaration, rebus sic stantibus and a primitivist view of the law of Nations”, op. cit., p. 1.

25 Dominik Moskvan, "The clash of intra-EU bilateral investment treaties with EU-law: A bitter pill to swallow”, en Columbia Journal of European Law 22 (2015), p. 110.

27 Michael J. GLennon, “How international rules die”, en Georgetown Law Journal 93 (2005), p. 940. 
representado por la circunstancia de que un Estado deje de cumplir lo prometido, esto, en aparente violación del precitado principio.

Se trataria, por tanto, no de explicar por qué las reglas son o no vinculantes, sino más bien de describir por qué los agentes pueden perseguir sus preferencias de manera más eficiente, en busca de maximizar su utilidad, y de hecho maximizándola, y de explicar por qué los agentes toman tales decisiones.

En ese sentido, el modelo de rational choice se concentraria en elementos de análisis económico (law and economics) para determinar los medios óptimos con el fin de maximizar las utilidades. ${ }^{28}$

Sin embargo, Glennon, como nosotros, le ve problemas a esta explicación, así: i) un modelo de rational choice terminaría por afirmar que solo hay una manera correcta de hacer las cosas, que es lo que se le critica, quizás en forma imprecisa, a defensores del derecho natural como nosotros; ii) los agentes tendrán siempre un gran número de preferencias, y no solo uno; igualmente, muchas utilidades que perseguir; iii) el modelo no cubriría la propensión a cometer errores cognitivos que tienen que ver con la vida doméstica de los agentes y, en particular, con los efectos de una política determinada acerca de ellos, de su autoestima, y en relación con el costo asumido en materia de reputación.

Así, no sería dable la posibilidad de una explicación y una predicción sistematizadas de conducta con dicho modelo. ${ }^{29}$

Una aproximación intermedia, que refleja una visión binaria entre los mundos del is (para nosotros equivalente a realidad) y del ought (mundo del deber ser) diría que un agente está obligado de manera contingente, es decir, que al adoptar una preferencia, se adopta otra serie de preferencias secundarias. ${ }^{30}$

Glennon pone los siguientes ejemplos:

Ejemplo 1. Si una persona decide manejar de Boston a Washington, eso implica haber escogido, también, llenar el tanque del carro con gasolina. Si lo que esa persona desea es llegar a Washington, entonces ella debe ir a la bomba de gasolina y llenar el tanque. De lo contrario no llegará. Así, esa persona está obligada a hacerlo. ${ }^{31}$

Ejemplo 2: ciertas obligaciones deben asumirse si es que no se desea que se materialicen, a su vez, ciertas consecuencias. Así, si una persona no paga sus deudas, sus activos eventualmente pueden serle embargados. Si la persona no desea que sus activos le sean embargados, entonces debe pagar sus deudas. 
En el ejemplo 1, si se asume que la persona está obligada a llenar el tanque de su automóvil habría que mirar a su vez dos cosas: i) cuánta gasolina le cabe al tanque (quizás solo 50 galones, en cuyo caso deberá ir a la bomba de gasolina, de pronto, en varias ocasiones), y ii) qué ocurre si al carro no se le pone gasolina, no solo desde el punto de vista de quien no lo hizo, sino, por ejemplo, de quien esperaba a esa persona en Washington a una hora determinada, es decir, de quien tiene una expectativa. ${ }^{32}$

Para Glennon, sobre la base de esos ejemplos, el término law, en un sentido coincidente con el DIP, no incluiria normas que son violadas por varios Estados.

Este autor se pregunta, no tanto si una norma de derecho internacional es obligatoria o no, ya que para él, al hablar de norma de DIP, la obligatoriedad se da por sentada, sino más bien se cuestiona acerca de qué hace a una norma obligatoria.

Este autor concluye que una norma viene a ser obligatoria en la medida en que los costos de una violación sean mayores que los beneficios que ella reporta, casi todo el tiempo y para casi todos los Estados. ${ }^{33}$

Así, en la medida en que una violación no represente mayores incidentes, habrá una suerte de umbral psicológico menor respecto de futuras violaciones, y una mayor probabilidad de no cumplimiento futuro.

Para ilustrar esto, Glennon utiliza la siguiente expresión: success breeds success, failure breeds failure. ${ }^{34}$

Si una norma ha sido violada un número repetido de veces, por ejemplo, el artículo 2 (4) de la Carta de la ONU, en un periodo de tiempo significativo, Glennon no llama eso derecho internacional. ${ }^{35}$ Habria más bien un conjunto de normas sociales que han sido objeto de un proceso de internalización y que influencian la conducta de los Estados, y, consiguientemente, también se darian dos problemas: i) determinar lo que es una violación, y ii) la perspectiva diferente de los agentes, es decir, cómo ven y perciben la realidad de manera distinta así estén presenciando la misma porción de ella.

En una aproximación que el mismo Glennon denomina en inglés epiphenomenal, él afirma por vía de ejemplo que Canadá no ataca a Mongolia, o Guatemala no ataca a otro país, lo que evidencia que el derecho internacional se cumple.

En ese sentido, y esto nos sirve para reforzar nuestra hipótesis, lo que es es lo que debe ser, solo que la apariencia alteraría la realidad, algo que se vería cuando quizás muchos tratadistas clásicos de derecho internacional quieren adscribir un

\footnotetext{
32 Ibid., p. 952.

33 Ibid., p. 953.

34 El éxito siembra éxito. El fracaso siembra fracaso.

35 Glennon, "How international rules die", ob. cit., p. 960. Ver el ejemplo de la segunda parte del artículo y el recurso eventual a la tortura por parte de Donald J. Trump.
} 
aparente cumplimiento a que los Estados se han enmarcado de manera obediente al mundo del deber ser. ${ }^{36}$

Ejemplo: el Estado $x$ no ocupa ilegalmente el Estado $z$ entre el momento $y$ y el momento $w$. Podría pensarse erróneamente, por parte de otros Estados, que el Estado $x$ cumple con la Carta de la ONU. Quizás el Estado $x$ solo haya contemplado un beneficio que excede el costo y el DIP se ha realizado sin su intervención.

La coincidencia entre el mundo del ser y el mundo del deber ser que defendemos también con nuestra hipótesis de trabajo puede encontrar fundamento en la tesis de Cohen, que busca preguntarse, no tanto por el cumplimiento o incumplimiento del derecho internacional, sino más bien por la definición de la disciplina. ${ }^{37}$

En nuestra opinión, sus hallazgos son fascinantes. Ciertamente creemos que él emprende una verdadera excursión hermenéutica cuando vuelve a preguntarse por qué y cuándo los Estados cumplen con el derecho internacional.

Cohen propone una triple división teórica, así: i) el derecho internacional fundamental (o core international law); ii) las reglas legitimadas, y (iii) el derecho internacional contentivo de aspiraciones.

El primero se subdividiría en: a) normas internalizadas y b) valores de proceso; las segundas se subdividirian en a) tratados y b) derecho consuetudinario, y el tercero comprendería normas derivadas de tratados que no han sido internalizadas. ${ }^{38}$

Los valores del proceso abarcarían caracteres tales como posibilidad de determinación, consistencia y rango (pedigree). Esta división buscaría, en palabras de Cohen, definir qué es derecho internacional que, como hemos afirmado en otras ocasiones, es lo que hace un Estado en un momento determinado, incluso por vía extralegal, siempre y cuando sea un régimen democrático, bajo una acepción limitada y precisa de lo que es democracia. ${ }^{39}$

Cohen utiliza las aproximaciones de Harold Koh y de Thomas Franck, la primera sobre procesos legales transnacionales e internalización de las normas, y la segunda sobre el abordaje de una teoria del derecho internacional como legitimidad. ${ }^{40}$

La tesis de Koh arguye que el derecho internacional obtiene su fuerza cuando sus reglas y normas son internalizadas por los actores dentro de los mismos Estados a través de un proceso de interacción e interpretación, con la advertencia de que la internalización no siempre es equivalente a aceptar que la norma es correcta (justa diriamos nosotros).

36 Ibid., p. 980.

37 CoHen, "Finding international law: Rethinking the doctrine of sources", op. cit., p. 67.

38 Ibid., p. 71.

39 Ibid., p. 77. Nosotros vamos quizás más allá que Cohen, cuando él afirma que el ought y el is están intrinsecamente relacionados. Por nuestra parte creemos que en el contexto del derecho internacional público coinciden o, si se quiere, son lo mismo. 
Para ilustrar su tesis, Harold Koh utiliza el ejemplo de la Convención Contra la Tortura y Otros Tratos o Penas Crueles, Inhumanos o Degradantes (en adelante, Convención contra la tortura), que finalmente fue aprobada en Estados Unidos, y que entró en vigor para ese país.

La tesis de Thomas Franck, por otro lado, identifica al derecho con legitimidad y relaciona cuatro factores principales que indican la legitimidad de una regla: i) la posibilidad de determinación; ii) la validación simbólica; iii) la coherencia y iv) la adhesión. ${ }^{41}$

Su tesis explicaría por qué un tratado negociado cara a cara tendría mayor cumplimiento que un tratado de derechos humanos multilateral, negociado sin mucho contacto entre los representantes de los Estados. Cohen insiste en que el problema no es tanto si una regla se cumple o no, sino más bien consiste en determinar qué es derecho y por qué se cumple, lo que en últimas viene a ser un examen de costos y beneficios. ${ }^{42}$

Queremos dilucidar, en el marco de la discusión sobre existencia y efectividad si, en últimas, hay una tensión o una imposibilidad de coexistencia pacífica entre el principio PSS y el artículo 62 de la CV (RSS).

Para los que enseñamos DIP este problema se puede ilustrar con un ejemplo: si los tratados válidamente celebrados (en el sentido de requisitos de validez) deben ser cumplidos por los Estados de buena fe, por qué entonces, ante un cambio de circunstancias, puede eso verse menguado o relativizado.

El problema semántico no es ajeno a nosotros y no solo hace más dificil esgrimir posturas éticas, sino que dificulta la conducción de las relaciones internacionales. No olvidar las molestias asociadas a la pregunta acerca de qué se entiende por validez, cumplimiento, cambio, fundamental, violación, y por DIP, es algo imperativo en este punto y subyace a toda la discusión que ahora nos proponemos ilustrar y criticar, esto aparte de algunos lineamientos y hallazgos jurisprudenciales, especificamente en Gabcikovo-Nagymaros y en Fisheries Jurisdiction, ${ }^{43}$ que en la lectura de Vagts constituyen decisiones jurisprudenciales que, por un lado, reafirman el examen sobre el objeto y fin de un tratado a la luz de una agenda política, por ejemplo, y, por otro, le atribuyen a la doctrina RSS un carácter de derecho consuetudinario, pero que al final lo que demuestran es que los jueces o árbitros, en últimas, no han hecho mayores pronunciamientos sobre la doctrina, quizás porque la mayoría de tratados modernos, o estipulan periodos fijos de duración o simplemente permiten que una parte se libere de las obligaciones pasado un tiempo. ${ }^{44}$

\footnotetext{
41 Ibid., p. 106.

42 Ibid., p. 115.

43 Detlev F. VAGTS, "Rebus revisited: Changed circumstances in treaty law", en Columbia Journal of Transnational Law 43 (2005), pp. 472-473.

44 Ibid., p. 475.
} 
Wendl, a la luz de Gabcikovo-Nagymaros, no sin razón, afirma que hay un umbral muy alto para cumplir los requerimientos de la cláusula $R S S .{ }^{45}$

Bederman defiende la que él llama una tesis primitivista. Con el fin de demostrar su postura, empieza por afirmar que al paso que el PSS es el primer principio y es derecho según una postura crítica tradicional, una apelación a la doctrina de RSS, según esa misma posición crítica, es (seria) pura politica disfrazada. ${ }^{46}$

Bederman hace un recuento histórico donde indica que a fines del siglo XVIII y a mediados del XIX argüir que las circunstancias pudieran cambiar de manera fundamental habría sido impensable, y que solo hasta 1870 la aplicación y el alcance de la doctrina de RSS se habría concretado y habría sido a partir de ese momento que los tratados empezaron a percibirse como hojas de papel susceptibles de ser rotas en caso de que surgieren asuntos percibidos como más relevantes o importantes.

La fundamentación de por qué poder legitimamente romper una promesa previa se remontaría a las tesis de Cicerón, que en su tratado sobre las obligaciones explica la razón de que en ciertas ocasiones no se debe (puede no) honrar una promesa. ${ }^{47}$ De acuerdo con Gordley, Graciano habría sostenido que siempre debe considerarse la opción menos pecaminosa.

Por ejemplo: si se prometió guardar la confidencialidad, pero esa confidencialidad supone no advertir que alguien será asesinado, ella entonces puede romperse. ${ }^{48}$ Por su parte, John Stuart Mill, ${ }^{49}$ citado por Bederman, habria afirmado que las naciones deben abstenerse de imponer condiciones no razonables que no puedan ser cumplidas, y que los tratados deben limitarse temporalmente en cuanto a su duración. Habría, de acuerdo con él, una distinción entre lo que es susceptible de ser exigido y aquello que no, finalmente entre lo moral y lo legal, cosa que hoy, según Bederman, sería aquella entre lo jurídico y lo político.

La Declaración de Londres de 1871 habría puesto de presente, por un lado, que alguien (algo) no debe ser el juez de su propia causa (todo lo contrario al contenido y alcance de la doctrina de RSS según el artículo 62 de la CV) y, por otro lado, el inicio de una nueva escuela de interpretación para abordar a su vez, de manera interpretativa, cómo modificar los tratados. ${ }^{50}$

45 Andreas WENDL, "International rights on the White Nile of the New State of South Sudan", en Boston College International and Comparative Law Review 39 (2016), p. 21.

46 Bederman, "The 1871 London Declaration, rebus sic stantibus and a primitivist view of the law of Nations", op. cit., p. 3.

47 Cicerón afirma, en el Libro I de Los Deberes (X), lo siguiente: "pues conviene recordar lo que establecí al principio como fundamentos de la justicia: primeramente, que a nadie se cause daño; después, que se provea a la común utilidad. Cuando con las circunstancias cambian esos fundamentos, cambia también el deber, y no siempre es el mismo. En efecto, puede suceder que resulte perjudicial a quien se prometió o a quien lo prometió, cumplir alguna promesa o convenio".

48 James GoRDLEY, "Impossibility and changed and unforeseen circumstances", en The American Journal of Comparative Law 52 (2004), p. 515.

$220 \quad 49$ Bederman, "The 1871 London Declaration, rebus sic stantibus and a primitivist view of the law of Nations”, op. cit., pp. 19-20.

50 Dice la Declaración de Londres de 1871 lo siguiente: "It is an essential principle of the law of nations that no power can liberate itself from the engagements of the treaty nor modify the sti- 
A pesar de que el espíritu de la Declaración de Londres de 1871, siguiendo a Bederman, no fue reconocida en la CV, la aparente contradicción entre la doctrina de PSS y la cláusula RSS no se habría resuelto ni al momento de confección de la CV ni mucho menos a fines del siglo XX, y nos atrevemos a pensar nosotros, tampoco en la actualidad.

Bederman menciona distintas aproximaciones como la denominada funcionalista, la llamada realista y la suya, etiquetada como primitivista, y afirma que la primera cree en la soberanía, la segunda no lo hace en punto de la cooperación, y la última es un retorno al estudio de una metafísica del derecho internaciones, particularmente de unos primeros principios en virtud de los cuales no se debiera hacer una distinción entre autoridad legal y autoridad moral y, por ende, no habría entonces cabida a una distinción positivista o naturalista,${ }^{51}$ lo que en últimas soportaría o fundamentaría la doctrina de RSS en el sentido de permitirle a los Estados tener la libertad, dentro de limites sustanciales definidos, de modificar o terminar las obligaciones derivadas de un tratado. ${ }^{52}$

Coincidimos con Bederman, sobre todo con su conclusión, en el sentido de ver la doctrina de RSS, no a través de una deconstrucción, lo cual no es posible, según su planteamiento, sino más bien a través de un desafío a lo que podría ser una idea fija de los tratadistas de derecho internacional: que los Estados no pueden o deben ser los jueces de sus propias causas, repetimos, no en el sentido procesal de los términos juez y juzgar, sino en un sentido metafísico: contemplar y materializar una idea de beneficio que en últimas se basa en unos principios generales, quizás no susceptibles de expresión en palabras, pero al menos sentibles.

Como parece sugerirlo Bederman en su texto, y algo respecto de lo cual estaríamos de acuerdo, nemo debet ese judex in propria causa, quizás no es algo que se evidencie en la realidad, cuando los Estados siempre son los principales artífices de sus propios juicios (self-judgment).

Y esto ocurre no solo con respecto a un cambio fundamental de circunstancias, sino también con respecto al mismo cumplimiento de los tratados a la luz del artículo 26 de la CV.

Un ejemplo puede ilustrar esto: el gobernante del país $x$, pasado un tiempo luego de haber entrado en vigor el tratado No. 1 considera que las obligaciones derivadas del mismo no le convienen a su país y decide buscar la terminación del instrumento internacional. Por otro lado, el gobernante del país $Z$, pasado un tiempo luego de

pulations thereof, unless with the consent of the Contracting Parties by means of an amicable arrangement". ["Es un principio fundamental del derecho de las naciones que ninguna potencia puede liberarse a sí misma de los vinculos de un tratado ni modificar sus disposiciones, a menos que se dé el consentimiento de las Partes Contratantes por medio de un acuerdo amigable”]. Esto se reproduce en una declaración de la Liga de las Naciones de abril de 1935.

51 Bederman, "The 1871 London Declaration, rebus sic stantibus and a primitivist view of the law of Nations", op. cit., p. 37.

52 Ibid., p. 38. 
haber entrado en vigor el tratado No. 2, considera que el instrumento internacional le reporta beneficios innegables a su país.

En ambos casos, un agente emite un juicio de valor respecto de las obligaciones derivadas.

En el primer caso ha operado un cambio en la valoración respecto de un momento original y un momento posterior. En el segundo también opera una valoración con respecto al cumplimiento del tratado. En ambos casos, el agente emite una valoración y el Estado se autojuzga (self-judgment).

Cohen afirma que, en últimas, así las circunstancias cambien, los Estados terminarán por tener como base al tratado mismo, ${ }^{53}$ algo que quizás, creemos, termine por tranquilizar un poco a los tratadistas tradicionales.

Con un planteamiento que de fondo reafirmaria una de las tesis que anunciábamos al principio de nuestro artículo, es decir, la sinonimia según Louis Henkin entre derecho y política, Chikere, en el contexto de un estudio sobre el papel de los tratados en el derecho internacional de la inversión extranjera, y de un estudio sobre la prevalencia de las fuentes de derecho internacional al tenor del artículo 38 del Estatuto de la CIJ, sostiene que al tiempo que la norma escrita viene a sustituir la no escrita, las normas políticas terminan por prevalecer sobre las legales. ${ }^{54}$ No nos queda claro a qué se refiere Chikere con normas politicas, pero creemos suponer correctamente lo que él señala: la mecánica de la política exterior de un Estado o, en general, de la política internacional, pero más ampliamente, la realidad, siempre terminan por prevalecer.

Si no se acepta la tesis de Bederman o, al menos, su nombre, los partidarios de una fundamentación del derecho natural como nosotros, le responderíamos amablemente -porque no estamos enteramente en desacuerdo con él- que al final no solo es la realidad, el mundo del ser, la que termina por imponerse, sino que en últimas es la naturaleza la única norma válida. ${ }^{55}$

Cohen cita en este sentido a Jack Straw: "if you have a set of rules which conflict with reality, then reality normally wins". ${ }^{56}$

Chikere sostiene, creemos con razón, que el principio PSS es una norma imperativa (jus cogens) y presenta algo que desde el punto de vista hermenéutico nos despierta interés.

Si, como lo anunciábamos, la mecánica de nuestra reflexión puede caracterizarse como hermenéutica porque busca auscultar el significado de los textos escritos

53 CoHEn, "Finding international law: Rethinking the doctrine of sources", op. cit., p. 89.

54 Eustace Chikere, "The place of treaties in international investment", en Annual Survey of International and Comparative Law 19 (2013), p. 163.

$22255 \quad$ Francisco, Laudato Si'. Sobre el cuidado de la casa común, Brooklyn, Melville, 2015, §115, p. 76.

56 Si hay un conjunto de normas que se encuentran en conflicto con la realidad, la realidad normalmente ganará. CoHEN, “Finding international law: Rethinking the doctrine of sources”,op. cit., p. 129. 
y, asimismo, el de la conducta de los Estados (que también, de manera amplia, pueden abordarse y tenerse como textos andantes) en punto de los artículos $26 \mathrm{y}$ 62 de la CV respectivamente, ¿qué ocurre cuando ya los agentes no son los jueces de su propia situación (no en el sentido procesal de la expresión juez), sino que unos jueces o árbitros, ahí sí en el sentido de litigio, llegan a conclusiones diferentes frente al alegato de un cambio de circunstancias?

Chikere identifica tres escenarios en el contexto del derecho internacional de la inversión extranjera: i) tribunales de arbitramento diferentes llegan a conclusiones diversas basándose en un mismo estándar derivado de un mismo tratado; ii) diferentes tribunales de arbitramento seleccionados bajo distintos tratados expiden laudos diferentes, pero con respecto a conflictos con los mismos hechos y con partes relacionadas, y iii) varios tribunales de arbitramento seleccionados bajo tratados diferentes pueden arribar a conclusiones diversas con respecto a disputas con hechos similares. ${ }^{57}$

Aparte de una eventual falta de diligencia de los agentes para prever cambios o incluso para comparar obligaciones entre dos o más tratados, y aun cuando la cláusula RSS pueda tenerse ampliamente como una excepción al principio PSS, Chikere considera que su aplicación ha sido escasa y aún en esos pocos casos, sin mucho éxito. ${ }^{58}$

Vagts recurre al law and economics y, a partir de un repaso histórico sobre la doctrina RSS que comprende un convenio de asistencia militar británico-holandés de 1585, la Declaración de Londres de 1871 y el Tratado de Berlín de $1878,{ }^{59}$ hace una referencia al artículo 2-615 del Uniform Commercial Code estadounidense y afirma que quizás, dado el paso del tiempo, las consecuencias derivadas de un cambio (negativas o indeseables afirmariamos nosotros) debieran ser asumidas por el agente que tenía una mejor posición para predecir el evento indeseable.

Si hemos entendido bien a Vagts, quizás un ejemplo ilustre lo que él quiere decir: el Estado $x$ suscribe un tratado comercial con el Estado $z$. La información macroeconómica y un repaso histórico de la conducta del Estado $x$ sugiere que no solo sus indices de crecimiento económico, sino también la solidez de sus instituciones democráticas harian predecir que cumplirá adecuadamente (es decir, de acuerdo con las expectativas creadas y de la manera más cercana posible, con el texto del instrumento) con las obligaciones durante un periodo razonable de tiempo.

Por otro lado, el Estado $z$ muestra todo lo contrario: debilidad de las instituciones, indices negativos de crecimiento, etc. Si hubiere un cambio de gobierno abrupto y una política de expropiaciones en el Estado $z$ que llevaran a $x$ o a $z$ a argumentar un cambio de circunstancias, quizás sería $x$ el que debiera llevar la peor parte. ${ }^{60}$

57 ChIKere, "The place of treaties in international investment", op. cit., p. 174.

58 Ibid., p. 185.

59 VAGTS, "Rebus revisited: Changed circumstances in treaty law", op. cit., p. 467.

60 Ibid., p. 462. 
De manera similar, Helmut Kohler via Gordley, se pronuncia al afirmar que siempre que se hable de una disrupción, hay que saber qué parte había asumido el riesgo del evento que ocurrió. ${ }^{61}$

En la medida en que la cláusula RSS inevitablemente fue influenciada por la filosofia moral aristotélica, esto significa que siempre cabe la pregunta acerca de bajo qué circunstancias las partes hubiesen deseado estar vinculadas por un compromiso, y también qué harían las partes como personas razonables si confrontasen anticipadamente los problemas a los que en un momento dado se enfrentarán. ${ }^{62}$ Fon y Parisi, por su parte, hacen un análisis sobre la objeción de un Estado al derecho consuetudinario naciente. Ellos consideran que el éxito de una objeción de un Estado a ese derecho consuetudinario naciente debería comprender los siguientes elementos: i) el Estado que quiere que su objeción sea exitosa debe informar a los demás Estados acerca de dicha circunstancia antes de que la práctica de los Estados se convierta en norma vinculante; ii) la objeción debe tener la forma de una declaración, de un voto o de una protesta; iii) a la luz de law and economics, la objeción plena es una estrategia no solamente para los Estados que consideran al derecho consuetudinario naciente como excesivamente oneroso, sino también para aquellos que quieren una ampliación o extensión del mismo. ${ }^{63}$

A pesar de que la cláusula RSS en el fondo pueda tener una connotación según la cual se sopesan los costos y los beneficios, y se busca que los últimos excedan a los primeros, este elemento no sería suficiente, salvo que los Estados se vieran sometidos a cargas insoportables. ${ }^{64}$

Fon y Parisi, citando a Ian Brownlie, afirman que si la apelación a la cláusula RSS no resultare exitosa, los que la invocan podrían acogerse a la subsequent objector doctrine (doctrina del objetante posterior), pero que en todo caso, los agentes deberán considerar los costos de reputación que tiene el objetar de manera anterior o posterior. ${ }^{65}$

\section{HACIA UNA PROPUESTA de SOluCión DEL PROBLEMA HERMENÉUTICO: LA DIVERSIDAD DE INTERPRETACIONES}

Creemos que la conducta del ser humano en interferencia intersubjetiva (o sea, las relaciones entre seres humanos), vista de forma exponencial, da luces definitivas sobre cómo es, en la realidad, el comportamiento de los Estados, y con ánimo predictivo, cómo será.

61 GoRder, "Impossibility and changed and unforeseen circumstances", op. cit., pp. 524-525.

62 Ibid., p. 526.

63 Vince Fon y Francesco PARISI, "Stability and change in international customary law", en Supreme Court Economic Review 17 (2009), pp. 285 y 291.

22464 Qué es carga insoportable quedaría al arbitrio de la valoración de un agente, valoración, creemos nosotros, sobre todo de corte político.

65 Fon y PARISI, "Stability and change in international customary law", op. cit., p. 309. 
Estimamos que el conjunto de las relaciones exteriores -que podría denominarse ampliamente como relaciones internacionales-, que como lo hemos afirmado en otras oportunidades de la mano de otros tratadistas, comparte una herencia intelectual común con el DIP, no es sino el reflejo de las vidas vividas de los seres humanos.

Si en el campo del derecho internacional de la inversión extranjera y a través de una lectura hermenéutica de los mundos del ser y del deber ser como lo expusimos en la primera sección, se puede sustentar de manera robusta la sinonimia de ellos e incluso una trasposición con el mundo del poder ser (might) que es lo que no solo aquí, sino en otras ocasiones hemos defendido, y que Erich Kaufmann vía von Bernstorff habria sintetizado en una máxima asi: "only those who can, may", ${ }^{6}$ un vínculo con la segunda sección de nuestro artículo no puede desconocer lo siguiente que queremos reiterar: de la Declaración de Londres de 1871 se podría deducir que los Estados que buscan dejar de cumplir sus obligaciones no pueden ser ellos mismos los que decidan o determinen autónomamente si hacerlo o no, sino que deben consultar el parecer de otros Estados.

Esto, en palabras de Bederman, no es otra cosa que afirmar que los Estados no pueden incurrir en un autojuzgamiento de su propia causa.

Hecha ya la advertencia en el sentido de que no nos hemos referido ampliamente ni tampoco lo haremos en los párrafos siguientes al sentido procesal de la palabra juzgar, es decir, aquel que involucra un proceso judicial o arbitral mediante la invocación de normas de DIP y que se resuelve mediante una adjudication, en aplicación, por ejemplo, tanto del Reglamento como del Estatuto de la CIJ, o de una cláusula arbitral contenida en un tratado, sino más bien al sentido de valoración del mundo del ser, sostendremos, de la mano de Bederman y no contra su postura, que en efecto tanto el principio PSS como la cláusula RSS, no son otra cosa que el permanente autojuzgamiento de las circunstancias y que, en forma aparentemente paradójica, resulta más concreto, práctico y útil que un pronunciamiento formal por vía de una sentencia (ruling) de una corte o un laudo (award) de un tribunal.

El problema involucra, además, no solo esa actividad de autojuzgamiento. Involucra también un proceso complicado por el cual se atribuyen significados a significantes dados dentro de un contexto, tanto a palabras (en la forma de declaraciones o statements) como a actos propiamente dichos, por ejemplo, la ocupación ilegal de un Estado por parte de otro Estado en contravención de la Carta de la ONU.

Un ejemplo puede ilustrar esto que pretendemos solucionar, al menos parcialmente, con nuestro artículo: en enero de 2017 se posesionó un nuevo presidente en Estados Unidos. De acuerdo con la información macroeconómica y con los índices disponibles para el público elaborados por instituciones internacionales como el Banco Mundial o por organizaciones no gubernamentales, ese país tiene el producto interno bruto más grande y los índices de gasto militar más altos del planeta.

66 "Solo aquellos que pueden, podrán” (Jochen von BERNSTORFF, "Recent books on international law. American Journal of International Law 103 (2009), p. 613). 
El actual presidente de Estados Unidos, el señor Donald J. Trump, manifestó en su campaña electoral que él recurriría a métodos equivalentes de tortura para eliminar al Estado islámico (ISIS). De acuerdo con la Convención contra la tortura, de la cual Estados Unidos es parte, ese país no podría (debería) recurrir a dichos métodos.

Supongamos que el señor Trump le ordena al ejército estadounidense que lo haga y se empiezan a evidenciar logros sorprendentes en materia de reducción de actos terroristas por parte de ISIS. Otros Estados siguen el ejemplo de Estados Unidos y las normas de la Convención contra la tortura devienen letra muerta.

Con independencia de una contraargumentación en el sentido de que dicho tratado contiene normas de jus cogens, ese escenario nos muestra la dificultad que supone un cambio de circunstancias entre, por ejemplo, 1970 cuando ISIS no existía y 2018 cuando en efecto sí.

¿Quién valora esas circunstancias? ¿Un juez de la CIJ? ¡No! Las valora quien vende periódicos en una calle en Nueva York, las valora un profesor de derecho internacional, pero, sobre todo, las valora el señor Trump y el Congreso de Estados Unidos. ¿Qué significado jurídico y metajurídico -por no decir metafísico- podemos darle a esa conducta del señor Trump, de los Estados Unidos y de todos los que somos testigos de ellas?

\section{¿Qué hay del texto (wording)?}

Ostrovsky y Reavis dicen que al nivel, por ejemplo, de Estados Unidos, esto se puede solucionar por vía de dos escuelas de interpretación: i) un tratado puede considerarse como estático en la medida en que sus disposiciones quedan congeladas y quizás sin interpretación al momento de ratificación por los Estados negociadores, o ii) un tratado puede considerarse como evolucionario, en cuyo caso el significado real de las palabras puede variar con el tiempo.

El primer caso es raro. ${ }^{67}$ Otro problema se presenta, también a nivel de Estados Unidos y puede ayudarnos a dilucidar el asunto de los significados de los textos, que consiste en la comparación de las obligaciones internacionales con la legislación interna por parte de quien interpreta las normas jurídicas: i) los actos del Congreso de Estados Unidos no pueden jamás interpretarse en el sentido de violar las leyes de las naciones. Para esto se cita como fundamento a Murray vs. Schooner Charming Betsy de 1804, y ii) la doctrina de lex posterior, que afirma que en caso de que la legislación doméstica y las obligaciones derivadas de un tratado se encuentren en conflicto, regirá la posterior en el tiempo siempre que la estipulación del tratado sea self-executing. ${ }^{68}$

67 Aaron A. Ostrovsky y Brandon E. ReAvIs, "Rebus sic stantibus: Notification of consular rights after Medellin”, en Michigan Journal of International Law 27 (2006), p. 670. 
De la mano del Justice John Marshall, Ostrovsky y Reavis describen las diferencias inaparentes entre la voluntad política del Estado en el caso de Estados Unidos (lo politico) y lo que es vinculante para las cortes (lo legal).

Al final la cláusula $R S S,{ }^{69}$ más que ver con un cambio de circunstancias, tendría que ver con un frame-shift en la voluntad política con respecto al derecho internacional y a las decisiones judiciales internacionales.

En últimas, los Estados emiten valoraciones constantes que involucran dos problemas cuya solución es dificil en nuestra opinión, y respecto de las cuales se han presentado algunas luces: i) los agentes tienen diferentes perspectivas de una situación fáctica, esto sin considerar las asimetrias de información, y ii) hay una discusión o debate continuos sobre qué es la verdad y sobre una sensación de justicia.

En 2017, Estados Unidos se retiró del Acuerdo de París, y el señor Trump arguyó varias razones para hacerlo. ¿Cómo convencer al señor Trump acerca del cambio climático y sus repercusiones negativas? ¿La percepción que el señor Trump tiene de justicia y verdad es la misma que tienen los agentes de otros Estados sobre la protección del medio ambiente? ¿Puede imponerse una visión sobre la otra? En el entretanto, ¿qué hacer con el texto del Acuerdo de París y sus disposiciones?

Por supuesto que excede el ámbito de este artículo la discusión sobre los alcances filosófico-jurídicos de las expresiones verdad y justicia, pero ambientan de manera adecuada los problemas de interpretación frente a un texto inicialmente vinculante y, por supuesto, frente a la conducta de un Estado o de un gobernante.

Argumentar que la interpretación de la realidad por parte de alguien en un momento determinado es diferente a la de otro, por ejemplo, cuando hay cambio de gobierno, y alegar así un cambio de circunstancias o eventualmente la aplicación de la cláusula RSS no deja de ser impensable aquí.

Inevitablemente, los ámbitos del deber ser, el ser y el poder ser se confunden en el mundo externo, y en el proceso de valoraciones continuas siempre hay apelación a contornos metafísicos (v. gr.: lo que en acápites anteriores se llamaban principios).

\section{CONCLUSIÓN}

Desde el punto de vista ontológico creemos que no resulta posible afirmar que el DIP no existe.

A lo largo de nuestro artículo hemos presentado algunas aristas de las aproximaciones multidimensionales provistas por el derecho internacional de la inversión

69 Ibid., p. 685. 
extranjera, el law and economics y algunas posturas filosófico-psicológicas con el fin de explicar si hay o no una coexistencia pacífica del principio PSS y de la cláusula RSS y, más ampliamente, para rebatir a aquellos que afirman que o el DIP no existe o no se cumple, o no se cumple porque no existe, o no existe porque no se cumple.

Contrariando un párrafo central de la Declaración de Londres de 1871, antecedente remoto de la doctrina $R S S$, y utilizando para el efecto a los exponentes de posturas realistas del DIP, afirmamos que luego de un examen hermenéutico de las conductas y palabras de los agentes, se puede concluir que son ellos siempre los jueces de su propia causa, sin necesidad de la intermediación de un tercero.

Quieran ellos cumplir y, de hecho, cumplan con las obligaciones de un tratado o no, o quieran ellos alegar y de hecho aleguen un cambio de circunstancias o no, lo que ocurre en últimas es una contemplación de los costos y beneficios en un momento determinado, que busca aproximarse a una concepción de lo que es beneficio, que para nosotros solo puede encontrar una fundamentación metafísica y que está imbuida de ella; por ejemplo, lo que para un agente determinado sea o represente un valor como la dignidad humana y cómo la llame, o un bien jurídico como la vida y cómo busque protegerlo.

Los mundos del ser (is), del deber ser (ought) y del poder ser (might) se confunden, entonces, en la práctica.

Debemos decir que la circunstancia de que no haya violaciones expresas del DIP puede denotar que ha primado el beneficio de no violarlo para un agente y no tanto que él busque cumplir el DIP.

Cuando el agente no actúa expresamente en contra de las disposiciones de DIP, este se verifica o realiza en el mundo externo, la realidad, pero no necesariamente porque el agente lo quiera o lo busque.

Creemos que este estado de cosas es más frecuente y común que la expedición de una sentencia o de un laudo arbitral, y es una forma realista como se puede observar la conducta de los Estados modernos.

Aunque la hipótesis de trabajo y las posturas que hemos mencionado no constituyen de ninguna manera una respuesta definitiva y final, y no representan el debilitamiento del derecho natural como fundamento del DIP, que es lo que defendemos nosotros, y que todavía queda mucho camino por recorrer respecto de las complejidades representadas por las dificultades que implica el estudiar las distintas perspectivas de los agentes y los alcances de las expresiones justicia y verdad, estimamos que recurrir al cuestionamiento de posturas tradicionales como el positivismo o el derecho natural (esta última de recibo por nosotros), por ejemplo, a través de behavioral economics, resulta un ejercicio no solo necesario, sino ilustrativo y útil en el contexto de una investigación sobre la efectividad del DIP. 


\section{BIBLIOGRAFÍA}

Bederman, David J., "The 1871 London Declaration, rebus sic stantibus and a primitivist view of the law of Nations", en American Journal of International Law 82, 1, (1998), pp. 1-39, doi: 10.2307/2202874.

Bilder, Richard B., Jochen Von Bernstorff y Volker Roeben, "Recent books on international law. International law as public law: On recent and historical approaches to international law", en American Journal of International Law 103, 3, (2009), pp. 609-619, en https://www.jstor.org/stable/40283678

CHIKERE, Eustace, "The place of treaties in international investment", en Annual Survey of International and Comparative Law 19 (2013), pp. 157-195, en https:// digitalcommons.law.ggu.edu/annlsurvey/vol19/iss1/9

Cohen, Harlan Grant, "Finding international law: rethinking the doctrine of sources", en Iowa Law Review 93 (2007), pp. 67-129, en https://digitalcommons. law.uga.edu/fac_artchop/936/

Damrosch, Lori F., Louis Henkin, Richard Crawford, Oscar Schachter, Hans Smit, International Law Cases and Materials, West, 2001.

Fon, Vincy y Francesco PARISI, "Stability and change in international customary law", en Supreme Court Economic Review 17 (2009), pp. 279-300.

Francisco, Laudato Si'. Sobre el cuidado de la casa común, Brooklyn, Melville, 2015.

GLennon, Michael J., "How international rules die", en Georgetown Law Journal 93 (2005), pp. 939-990, en https://ssrn.com/abstract=752987

GoRDLEY, James, "Impossibility and changed and unforeseen circumstances", en The American Journal of Comparative Law 52 (2004), pp. 515-526, doi: $10.2307 / 4144477$

Koеск, Heribert Franz, "The 'changed circumstances', clause after the UN Conference on the Law of the Treaties (1968-1969)", en Georgia Journal of International \& Comparative Law 4 (1974), pp. 93-114, en http://digitalcommons. law.uga.edu/cgi/viewcontent.cgi?article=2220\&context=gjicl

Moskvan, Dominik, "The clash of intra-EU bilateral investment treaties with EU-law: A bitter pill to swallow", en Columbia Journal of European Law 22 (2015), pp. 101-195, en https://heinonline.org/HOL/P?h=hein.journals/coljeul22\&i=107

Organización de las Naciones Unidas, "Acuerdo de París", en http://unfccc.int/files/essential_background/convention/application/pdf/spanish_paris_agreement.pdf

Organización de las Naciones Unidas, "Carta de derechos y deberes económicos de los Estados", en http://www.un.org/ga/search/view_doc. asp?symbol=a/res/3281(XXIX)\&referer=http://legal.un.org/avl/ha/cerds / cerds.html\&Lang $=\mathrm{S}$ 
Organización de las Naciones Unidas, "Carta de las Naciones Unidas”, en http:// www.un.org/es/charter-united-nations/index.html

ORganización de LAS NACIONES Unidas, "Convención contra la tortura y otros tratos o penas crueles, inhumanos o degradantes", en http://www.ohchr.org/SP/ Professionallnterest/Pages/CAT.aspx

Organización de las Naciones Unidas, “Convención de Viena de 1969”, en https:// treaties.un.org/doc/publication/unts/volume\%201155/volume-1155-i18232-english.pdf

Organización de las Naciones Unidas, "Resolución 1803 (XVII) de la Asamblea General del 14 de diciembre de 1962, titulada 'Soberania permanente sobre los recursos naturales”, en http://www.ohchr.org/SP/ProfessionalInterest/Pages/NaturalResources.aspx

ORGANIZACIÓn DE las NaCiones Unidas, "Resolución 626 (VII) de la Asamblea General del 21 de diciembre de 1952 titulada 'Derecho a explotar libremente las riquezas y recursos naturales"”, en http://www.un.org/es/comun/docs/?symbol=A/ RES/626(VII)\&Lang=S\&Area=RESOLUTION

Ostrovsky, Aaron A. y Brandon E. Reavis, "Rebus sic stantibus: notification of consular rights after Medellin”, en Michigan Journal of International Law 27, 2, (2006), pp. 670-685, en https://search.proquest.com/docview/208561841

Repousis, Odysseas G. y James Fry, "Armed conflict and state succession in investor-state arbitration”, en Columbia Journal of International Law 22 (2016), pp. 422-429, en https://ssrn.com/abstract=3013226

TÉllez NúÑEz, Andrés, El problema de la efectividad del derecho internacional público, Bogotá, Javegraf, 2008, pp. 1-10.

VAGTs, Detlev F., "Rebus revisited: Changed circumstances in treaty law", en Columbia Journal of Transnational Law 43, 2, (2005), pp. 461-474, en http://jtl. columbia.edu/rebus-revisited-changed-circumstances-in-treaty-law/

Webb Yackee, Jason, "Pacta sunt servanda and state promises to foreign investors before bilateral investment treaties: myth and reality", en Fordham International Law Journal 32, 5, (2009), pp. 1550-1613, en https://ir.lawnet.fordham. edu/ilj/vol32/iss5/5

Wendu, Andreas, "International rights on the White Nile of the New State of South Sudan", en Boston College International and Comparative Law Review 39, 1, (2016), pp. 1-21, en https://lawdigitalcommons.bc.edu/iclr/vol39/iss 1/2 